\title{
Entanglement of charge transfer, hole doping, exchange interaction, and octahedron tilting angle and their influence on the conductivity of $\mathrm{La}_{1-\mathrm{x}} \mathrm{Sr}_{\mathrm{x}} \mathrm{Fe}_{0.75} \mathrm{Ni}_{0.25} \mathrm{O}_{3-\delta^{*}}$ A combination of $\mathrm{x}$-ray spectroscopy and diffraction
}

\author{
Selma Erat, ${ }^{1,2, a)}$ Artur Braun, ${ }^{1, b)}$ Cinthia Piamonteze, ${ }^{3}$ Zhi Liu, ${ }^{4}$ Alejandro Ovalle, ${ }^{1}$ \\ Hansjürgen Schindler, ${ }^{1}$ Thomas Graule, ${ }^{1,5}$ and Ludwig J. Gauckler ${ }^{2}$ \\ ${ }^{1}$ Laboratory for High Performance Ceramics, Empa-Swiss Federal Laboratories for Materials Science and \\ Technology, CH-8600 Dübendorf, Switzerland \\ ${ }^{2}$ Department of Materials, Nonmetallic Inorganic Materials, ETH Zurich-Swiss Federal Institute of \\ Technology, CH-8093 Zurich, Switzerland \\ ${ }^{3}$ Swiss Light Source, Paul Scherrer Institut, CH-5232 Villigen PSI, Switzerland \\ ${ }^{4}$ Advanced Light Source, Ernest Orlando Lawrence Berkeley National Laboratory, Berkeley, California \\ 94720, USA \\ ${ }^{5}$ Technische Universität Bergakademie Freiberg, D-09596 Freiberg, Germany
}

(Received 3 May 2010; accepted 24 October 2010; published online 23 December 2010)

\begin{abstract}
Substitution of $\mathrm{La}$ by $\mathrm{Sr}$ in the $25 \% \mathrm{Ni}$ doped charge transfer insulator $\mathrm{LaFeO}_{3}$ leads to structural changes that inflect the electrical conductivity, which is caused by small polaron hopping via charge transfer and exchange interactions. The substitution forms electron holes and causes a structural transition from orthorhombic to rhombohedral symmetry, and then to cubic symmetry. The structural crossover is accompanied by a crossover from the $\mathrm{Fe}^{3+}-\mathrm{O}^{2-}-\mathrm{Fe}^{3+}$ superexchange interaction to the $\mathrm{Fe}^{3+}-\mathrm{O}^{2-}-\mathrm{Fe}^{4+}$ double exchange interaction in the course of substitution, as evidenced by a considerable increase in the conductivity at ambient temperature. The charge transfer and exchange interactions depend on the superexchange angle, which approaches $180^{\circ}$ upon increasing $\mathrm{Sr}$ concentration. An increase in superexchange angle leads to an increase in overlapping between the $\mathrm{O} 2 p$ and the $\mathrm{Fe} / \mathrm{Ni} 3 d$ orbitals. (C) 2010 American Institute of Physics. [doi:10.1063/1.3517822]
\end{abstract}

\section{INTRODUCTION}

Anions in ionic compounds play a decisive role in the electronic transport properties of these materials. For example, the oxygen in the $\mathrm{ABO}_{3}$-type perovskites mediates electron hopping between its neighboring cations, $\mathrm{B}^{3+}$ and $\mathrm{B}^{4+}$, by exchange interactions where the oxidation state and the spin state of the B metal ions determine whether hopping across oxygen can take place. ${ }^{1,2}$ Particularly, substitution in mixed valence compounds containing magnetic metal ions shows how conductivity is heavily influenced by these exchange interactions and corresponding magnetovolume effects, which goes along with changes in lattice spacing and crystallographic symmetry.

Spin related exchange interaction, also referred to as superexchange, is the antiferromagnetic coupling between two next-to-nearest neighbor positive ions through a nonmagnetic anion, such as oxygen. ${ }^{2}$ It strongly depends on the electronic and crystallographic structure such as electron occupancy, orbital configuration, and geometry, respectively. ${ }^{3}$ In the case of double exchange, the electrons move between positive ions having different $d$-shell occupancy via a nonmagnetic anion. ${ }^{1}$

The electronic conductivity of perovskites is generally explained in terms of small polaron transport ${ }^{4}$ where electrons hop from one B-site across, for example, to another $\mathrm{B}$-site via the $\mathrm{B}-\mathrm{O}-\mathrm{B}$ bridge. The interaction depends on the

\footnotetext{
${ }^{a)}$ Electronic mail: selmaerat33@gmail.com.

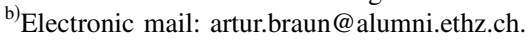

orbital overlap of the anion and the B-site cation, and thus, on the $\mathrm{B}-\mathrm{O}$ distance and $\mathrm{B}-\mathrm{O}-\mathrm{B}$ superexchange angle. ${ }^{5}$ A-site substitution in iron perovskites is well studied and relatively well understood. B-site substitution is less well studied. At the molecular scale, the structure of the perovskite includes the valence state of the A-site and B-site cations, and the spin state of the B-site cations, and the oxygen deficiency.

$\mathrm{LaFeO}_{3}$ is a well known $\mathrm{ABO}_{3}$-type perovskite with orthorhombic symmetry $(\mathrm{a}=5.5647 \AA, \mathrm{b}=7.8551 \AA$, and $\mathrm{c}$ $=5.5560 \AA)$ and an antiferromagnetic insulator with a Neel temperature $\mathrm{T}_{\mathrm{N}}=750 \mathrm{~K} .^{6}$ When the trivalent $\mathrm{La}$ is substituted by the divalent $\mathrm{Sr}$, which also has a larger ion radius than La, one electron hole is created at the oxygen site. The size difference of the cation radii constitutes a chemical pressure. $^{7}$ This effect decreases the rhombohedral lattice distortion. The end member of the substitution, $\mathrm{SrFeO}_{3}$, has cubic symmetry, which in turn increases the overlap between O $2 p$ and $\mathrm{Fe} 3 d$ orbitals. $^{8}$ In response to the electron hole created, Fe becomes oxidized from $\mathrm{Fe}^{3+}$ toward $\mathrm{Fe}^{4+}$ with a parallel increase in the conductivity.

Recently, perovskites such as $\mathrm{LaFe}_{1-\mathrm{y}} \mathrm{Ni}_{\mathrm{y}} \mathrm{O}_{3-\delta}$, ${ }^{6,9-11}$ and $\mathrm{La}_{1-\mathrm{x}} \mathrm{Sr}_{\mathrm{x}} \mathrm{Fe}_{1-\mathrm{y}} \mathrm{Ni}_{\mathrm{y}} \mathrm{O}_{3-\delta}$ (Refs. 12 and 13) have received much attention. They show a high electronic conductivity in the temperature range from 400 to $600{ }^{\circ} \mathrm{C}$, are good oxygen catalysts and exhibit sufficient stability at elevated temperatures. They would thus be a promising cathode material for intermediate temperature solid oxide fuel cells (IT-SOFC). ${ }^{14}$ Such complex perovskites are members of strongly corre- 
lated electron system and also received much attention from the point of electronic structure. For example, Sarma et al. ${ }^{15}$ Kumar et al. ${ }^{16}$ worked on $\mathrm{LaFe}_{1-\mathrm{y}} \mathrm{Ni}_{\mathrm{y}} \mathrm{O}_{3-\delta}$; Abbate et al., ${ }^{17}$ Chainani et al., ${ }^{18}$ and Wadati et al. ${ }^{19}$ worked on $\mathrm{La}_{1-\mathrm{x}} \mathrm{Sr}_{\mathrm{x}} \mathrm{FeO}_{3-\delta}$.

We have recently presented detailed experimental soft $\mathrm{x}$-ray absorption studies on $\mathrm{La}_{1-x} \mathrm{Sr}_{x} \mathrm{Fe}_{0.75} \mathrm{Ni}_{0.25} \mathrm{O}_{3-\delta}$ covering the oxygen $\mathrm{K}$-edge, and the iron L-edges, supported by ligand field multiplet calculations (LFMCs). ${ }^{20,21}$ We showed two different mechanisms which affect the electrical conductivity: d-type $\left[\mathrm{Fe}^{4+} /\left(\mathrm{Fe}^{4+}+\mathrm{Fe}^{3+}\right)\right]$ and p-type $\left\{\mathrm{e}_{\mathrm{g}}(\uparrow) /\left[\mathrm{t}_{2 \mathrm{~g}}(\downarrow)\right.\right.$ $\left.\left.+\mathrm{e}_{\mathrm{g}}(\downarrow)\right]\right\}$ electron holes created on the $\mathrm{Fe}$ and $\mathrm{O}$ sites, respectively. We concluded from these studies that p-type electron holes are mainly caused by charge transfer from $\mathrm{O} 2 p$ to $\mathrm{Ni} 3 d$ rather than to $\mathrm{Fe} 3 d$ orbitals.

In the present work we discuss the changes in the crystallographic structure upon $\mathrm{Sr}$ doping (i.e. symmetry, $\mathrm{Fe} /$ $\mathrm{Ni}-\mathrm{O}$ distance, superexchange angle) which affect the hopping process $\left(\mathrm{Fe}^{3+}-\mathrm{O}^{2-}-\mathrm{Fe}^{3+} / \mathrm{Fe}^{4+}\right)$ by either superexchange or double exchange and charge transfer process and consequently electronic conductivity. An increase in the tolerance factor is paralleled to an increase in symmetry. We also discuss the effect of the A-site Coulomb potential on the B-site which also plays an important role on the conductivity.

\section{EXPERIMENTAL SECTION}

$\mathrm{La}_{1-\mathrm{x}} \mathrm{Sr}_{\mathrm{x}} \mathrm{Fe}_{0.75} \mathrm{Ni}_{0.25} \mathrm{O}_{3-\delta}$ (LSFN) with $\mathrm{x}=0.0,0.25,0.50$, $0.75,1.0$, and $\mathrm{LaFeO}_{3}$ were prepared by conventional solid state reaction. The precursors $\mathrm{La}_{2} \mathrm{O}_{3}(>99.99 \%), \mathrm{SrCO}_{3}$ (99.9\%), $\mathrm{Fe}_{2} \mathrm{O}_{3}(>99.0 \%)$, and $\mathrm{NiO}(99.8 \%)$ were mixed in stoichiometric proportions, calcined at $1200^{\circ} \mathrm{C}$ for $4 \mathrm{~h}$ and then sintered at $1400{ }^{\circ} \mathrm{C}$ for $12 \mathrm{~h}$ with heating/cooling rate of $5 \mathrm{~K} / \mathrm{min}$. for $\mathrm{LSFN}$. $\mathrm{LaFeO}_{3}$ was calcined at $1200{ }^{\circ} \mathrm{C}$ for $(4 \mathrm{~h}+4 \mathrm{~h})$ with the same heating/cooling rate. X-ray powder diffractograms were collected with a Philips X'Pert PRO-MPD diffractometer at ambient temperature $(40 \mathrm{kV}, 40$ $\mathrm{mA}, \mathrm{Cu} K_{\alpha} \lambda=1.5405 \AA$ A) in steps of $0.02^{\circ}$ for $20^{\circ} \leq 2 \theta$ $\leq 80^{\circ}$. Rietveld structure refinement was performed with GSAS. ${ }^{22,23}$ The oxygen deficiency $\delta$ of the samples was obtained by thermogravimetry. ${ }^{21}$

Near edge x-ray absorption fine structure spectra at 300 $\mathrm{K}$ were recorded at the Advanced Light Source in Berkeley, Beamline 9.3.2, the end station of which has an operating energy range of 200-1200 eV and an energy resolution of $1 / 10000$. The vacuum chamber base pressure was lower than $5 \times 10^{-10}$ Torr. Signal detection was made in total electron yield mode. Powder samples were dispersed on conducting carbon tape and then mounted on a copper sample holder. Iron L-edge spectra were recorded from 690 to $750 \mathrm{eV}$, Oxygen K-edge spectra were recorded from 520 to $560 \mathrm{eV}$ in steps of $0.1 \mathrm{eV}$.

For the conductivity measurements, the calcined powders were pressed into bars with dimensions of about $5 \mathrm{~mm} \times 3 \mathrm{~mm} \times 25 \mathrm{~mm}$ and sintered at $1400{ }^{\circ} \mathrm{C}$ for $12 \mathrm{~h}$ with heating/cooling rate of $5 \mathrm{~K} / \mathrm{min}$. Four Pt terminals were applied on the sintered bars using Pt paint (CL11-5100, W. C. Heraeus GmbH \& Co. KG, Germany) and calcined with

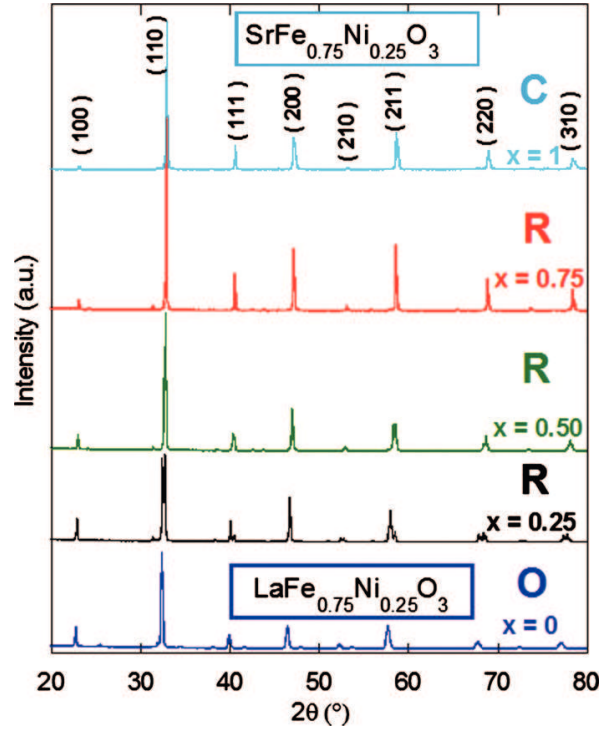

FIG. 1. (Color) $\mathrm{X}$-ray diffractograms for $\mathrm{La}_{1-\mathrm{x}} \mathrm{Sr}_{\mathrm{x}} \mathrm{Fe}_{0.75} \mathrm{Ni}_{0.25} \mathrm{O}_{3-\delta} ; \mathrm{x}=0$ orthorhombic (o); $\mathrm{x}=0.25,0.50,0.75$ rhombohedral (r); 1.0 cubic phase (c).The pure perovskite phase is indexed with all Bragg reflections as the cubic phase on top of the patterns.

heating/cooling rate of $5 \mathrm{~K} / \mathrm{min}$ up to $1000{ }^{\circ} \mathrm{C}$ with $45 \mathrm{~min}$. dwell time at $1000{ }^{\circ} \mathrm{C}$, and then cooled down to ambient temperature. $^{21}$

\section{RESULTS}

\section{A. Crystallographic structure}

The evolution of the crystallographic structure, as reflected by the $\mathrm{x}$-ray diffractograms in Fig. 1 shows that LSFN undergoes structural transformation upon substitution of La by Sr. The visually best match can be made for the end members with $\mathrm{x}=0$ for orthorhombic and with $\mathrm{x}=1.0$ for cubic symmetry. For the intermediate mixed members (x $=0.25,0.50$, and 0.75), clear distinction between cubic and orthorhombic symmetry cannot be made without deeper analysis of the diffraction data, which will follow in this section.

The Bragg reflections shift toward larger diffraction angles with increasing $\mathrm{Sr}$ substitution, revealing a general trend of decreasing unit cell volumes. For $\mathrm{x}=0$, the (110) reflection is virtually a single peak, which however splits into a distinct double peak for $\mathrm{x}=0.25$ in the rhombohedral phase. For $\mathrm{x}=0.50$ and 0.75 , the splitting gets diminished. The peak splitting decreases with increasing $\mathrm{Sr}$ content from 0.25 to 0.50 . For $x=0.50$, a clear peak splitting cannot be made out but the peak shows an asymmetric shape. For $\mathrm{x}$ $=0.75$, no clear peak splitting is observed but a small shoulder appears on the right side. The gradual decrease in the peak splitting can be considered as a second order phase transformation to higher crystal symmetry. ${ }^{24}$

It is known that the transport and magnetic properties of perovskites are sensitive to even minute structural imbalances such as tilting of the $\mathrm{BO}_{6}$ octahedra. In particular, parameters like bond length and bond angle determine orbital overlap and thus charge transfer and exchange interactions. We have quantified the structural details and changes for $\mathrm{x}$ 

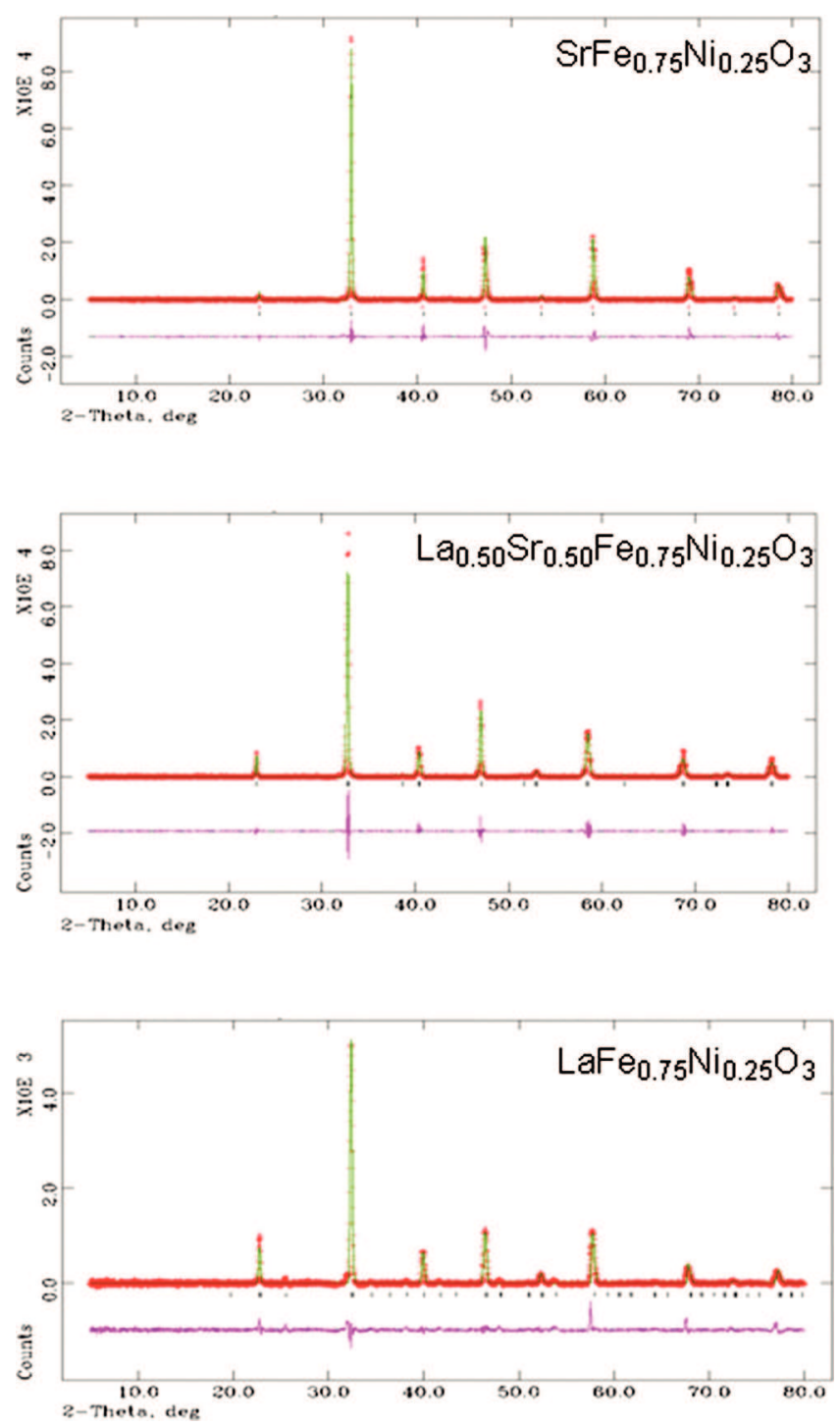

FIG. 2. (Color) Rietveld refinement profile of $\mathrm{LaFe}_{0.75} \mathrm{Ni}_{0.25} \mathrm{O}_{3-\delta}(\mathrm{x}=0)$, $\mathrm{La}_{0.5} \mathrm{Sr}_{0.5} \mathrm{Fe}_{0.75} \mathrm{Ni}_{0.25} \mathrm{O}_{3-\delta}(\mathrm{x}=0.50)$ and $\mathrm{SrFe}_{0.75} \mathrm{Ni}_{0.25} \mathrm{O}_{3-\delta}(\mathrm{x}=1.0)$. Experimental pattern (red), calculated pattern (green), difference pattern (bottom) are shown.
$=0.0, x=0.50$, and $x=1.0$ in Fig. 2 with Rietveld analysis. ${ }^{25}$ Orthorhombic symmetry with space group Pbnm (62) could be confirmed for $\mathrm{x}=0$. Pbnm is a pseudocubic space group and the unit cell parameters are related to the ideal cubic perovskites as $\mathrm{a} \approx \sqrt{2} \mathrm{a}_{\mathrm{p}}, \mathrm{b} \approx \sqrt{2} \mathrm{a}_{\mathrm{p}}$, and $\mathrm{c} \approx 2 \mathrm{a}_{\mathrm{p}}$. In Glazer's notation this tilting system is written as $\left(a^{+} b^{-} b^{-}\right) .{ }^{26}$ For LSFN with $\mathrm{x}=0.25,0.50$, and 0.75 Rietveld analysis yields rhombohedral symmetry with space group $R \overline{3} c$ (167). The rhombohedral distortion is a consequence of equivalent antiphase octahedra tilting along three crystallographic axes, i.e., a-a-a-following Glazer's notation. ${ }^{26}$ Finally, LSFN with $\mathrm{x}=1.0$ has cubic symmetry with space group $\operatorname{Pm} \overline{3} m$ (221). The samples with mixed phase of $\mathrm{La}$ and $\mathrm{Sr}$ show a very small peak at around $31.3^{\circ}$ due to minor contamination by a tetragonal phase which we could match with a nickelate phase (Joint Committee for Powder Diffraction Standard 01081-2084, $\mathrm{La}_{1.71} \mathrm{Sr}_{0.19} \mathrm{NiO}_{3.9}$ ).

The unit cell parameters $(\mathrm{a}, \mathrm{b}, \mathrm{c})$, volume $(\mathrm{V})$, interatomic distance for $\mathrm{Fe} / \mathrm{Ni}-\mathrm{O}$, average superexchange angle, and average tilting angle $\langle\omega\rangle$ as determined by Rietveld structure refinement are summarized in Table I.

With increasing Sr substitution, the symmetry of the system LSFN increases from orthorhombic to rhombohedral, and then to cubic. The changes in lattice parameters and unit cell volume depending on $\mathrm{Sr}$ doping concentration are illustrated in Figs. 3(a) and 3(b), respectively.

Since LSFN with $x=0$ has orthorhombic symmetry, two different oxygen positions ( $\mathrm{O} 1$ and $\mathrm{O} 2)$ exist with equal relative occupancy of $\mathrm{O} 1(50 \%)$ and $\mathrm{O} 2(50 \%)$. In addition there are two different distances between $\mathrm{Fe} / \mathrm{Ni}-\mathrm{O} 2$ which have also equal concentration $(25 \%)$ and which are labeled $\mathrm{O} 2^{(1)}$ and $\mathrm{O} 2^{(2)}$. In the following, thus, we will consider the weighted arithmetic average distance for $\mathrm{Fe} / \mathrm{Ni}-\mathrm{O}$ for comparison with the other samples:

TABLE I. Refined structure parameters for $\mathrm{La}_{1-\mathrm{x}} \mathrm{Sr}_{\mathrm{x}} \mathrm{Fe}_{0.75} \mathrm{Ni}_{0.25} \mathrm{O}_{3-\delta}$. [Atomic positions for Pbnm are 4(c) (x, y, 1/4) for La, and 4(b) (1/2, 0, 0) for Fe/Ni, and $4(\mathrm{c})(\mathrm{x}, \mathrm{y}, 1 / 4)$ for O1, and 8(d) (x, y, z). The refined positions are 4(c) $(0.0026,0.02385,1 / 4)$ for La, and 4(c) $(0.040,0.4959,1 / 4)$ for O1 and 8(d) $(-0.2916$, $0.2582,0.0542)$ for $\mathrm{O} 2$. Atomic positions for $R \overline{3} c$ are $6(\mathrm{a})(0,0,1 / 4)$ for $\mathrm{La} / \mathrm{Sr}$, and $6(\mathrm{~b})(0,0,0)$ for $\mathrm{Fe} / \mathrm{Ni}$, and $8(\mathrm{e})(\mathrm{x}, 0,1 / 4)$ for $\mathrm{O}$. The refined positions are $8(\mathrm{e})(0.447,0,1 / 4)$ for the sample $\mathrm{x}=0.25$, and $8(\mathrm{e})(0.475,0,1 / 4)$ for the sample $\mathrm{x}=0.50$, and $8(\mathrm{e})(0.508,0,0.25)$ for the sample $\mathrm{x}=0.75$. Atomic positions for $P m \overline{3} m$ are $6($ a) $(1 / 2,1 / 2,1 / 2)$ for $\mathrm{Sr}, 6(\mathrm{~b})(0,0,0)$ for $\mathrm{Fe} / \mathrm{Ni}$, and $18(\mathrm{e})(1 / 2,0,0)$ for $\mathrm{O}$.]

\begin{tabular}{|c|c|c|c|c|c|c|c|c|}
\hline $\mathrm{x}$ & Symmetry & $\begin{array}{c}\mathrm{a} \\
(\AA)\end{array}$ & $\begin{array}{l}\mathrm{b} \\
(\AA)\end{array}$ & $\begin{array}{l}\mathrm{c} \\
(\AA)\end{array}$ & $\begin{array}{l}\mathrm{V} \\
\left(\AA^{3}\right)\end{array}$ & $\begin{array}{c}\mathrm{Fe} / \mathrm{Ni}-\mathrm{O} \\
(\AA)\end{array}$ & $\begin{array}{c}\text { Superexchange angle } \\
(\text { deg })\end{array}$ & $\begin{array}{c}\text { Tilting angle }\langle\omega\rangle \\
\text { (deg) }\end{array}$ \\
\hline \multirow[t]{8}{*}{0.00} & Orthorhombic & 5.5326 & 5.5127 & 7.8254 & 238.674 & (O1) & 167.1(22) & 6.45 \\
\hline & & & & & & $1.9690(4)$ & & \\
\hline & & & & & & & $153.0(6)$ & 13.50 \\
\hline & & & & & & $(\mathrm{O} 2)^{(1)}$ & & \\
\hline & & & & & & & $153.0(6)$ & 13.50 \\
\hline & & & & & & $1.880(10)$ & & \\
\hline & & & & & & $(\mathrm{O} 2)^{(2)}$ & & \\
\hline & & & & & & $2.135(10)$ & & \\
\hline 0.25 & Rhombohedral & 5.5165 & 5.5165 & 13.365 & 352.229 & 1.96550 & 162.760 & 8.62 \\
\hline 0.50 & Rhombohedral & 5.4568 & 5.4568 & 13.422 & 346.116 & 1.93670 & 171.966 & 8.03 \\
\hline 0.75 & Rhombohedral & 5.4549 & 5.4549 & 13.3179 & 343.195 & 1.92700 & $177.4(34)$ & 1.30 \\
\hline 1.00 & Cubic & 3.85158 & 3.85158 & 3.85158 & 57.118 & 1.92558 & 180 & 0 \\
\hline
\end{tabular}



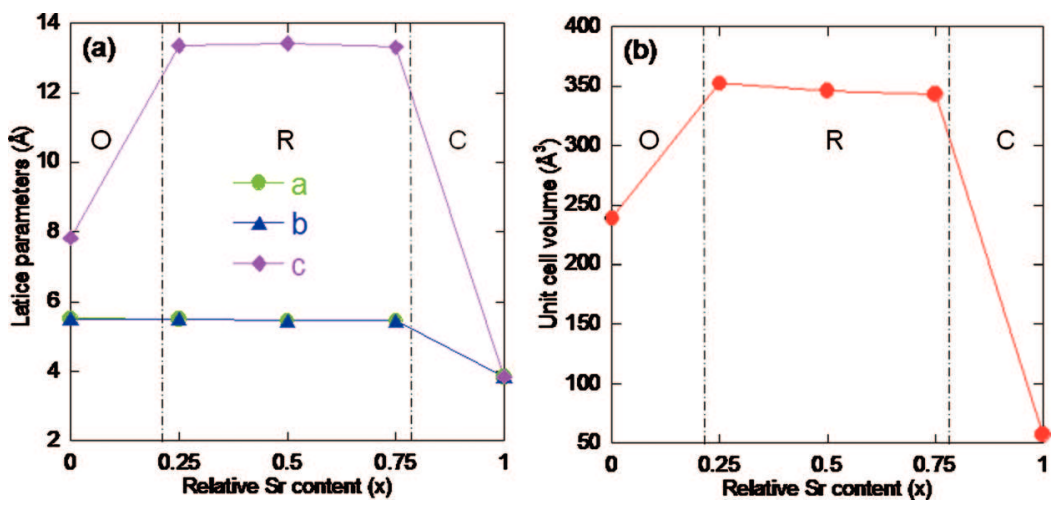

FIG. 3. (Color) The changes in (a) lattice parameters and (b) unit cell volume of $\mathrm{La}_{1-\mathrm{x}} \mathrm{Sr}_{\mathrm{x}} \mathrm{Fe}_{0.75} \mathrm{Ni}_{0.25} \mathrm{O}_{3-\delta}$ obtained by Rietveld refinement.

$$
\begin{aligned}
(\mathrm{Fe} / \mathrm{Ni}-\mathrm{O})= & \frac{1}{2}(\mathrm{Fe} / \mathrm{Ni}-\mathrm{O})+\frac{1}{4}\left(\mathrm{Fe} / \mathrm{Ni}-\mathrm{O}^{(1)}\right) \\
& +\frac{1}{4}\left(\mathrm{Fe} / \mathrm{Ni}-\mathrm{O}^{(2)}\right)
\end{aligned}
$$

The superexchange angle $\theta$, which is formed by the $\mathrm{B}-\mathrm{O}-\mathrm{B}$ $(\mathrm{Fe} / \mathrm{Ni}-\mathrm{O}-\mathrm{Fe} / \mathrm{Ni})$ bridge in $\mathrm{ABO}_{3}$ type perovskites, is $180^{\circ}$ for cubic symmetry. The deviation of $\theta$ from $180^{\circ}$ which is due to distortion in $[\mathrm{Fe} / \mathrm{Ni}] \mathrm{O}_{6}$ octahedra, is called tilting angle, and is directly related with the superexchange angle: ${ }^{24}$ $\langle\omega\rangle=1 / 2\langle 180-\langle\theta\rangle\rangle$.

In order to compare the superexchange and tilting angle of the samples the weighted angles are considered for $\mathrm{x}=0$.

The Goldschmidt tolerance factor t (Refs. 27-30)

$$
\mathrm{t}=\left(\mathrm{r}_{\mathrm{A}}+\mathrm{r}_{\mathrm{O}}\right) / \sqrt{2}\left(\mathrm{r}_{\mathrm{O}}+\mathrm{r}_{\mathrm{B}}\right)
$$

allows us to estimate the degree of the distortion in the perovskites. Since we have two different species on the A ( $\mathrm{La}$ and $\mathrm{Sr}$ ) sites and the $\mathrm{B}\left(\mathrm{Fe}\right.$ and $\mathrm{Ni}$ ) sites of the $\mathrm{ABO}_{3}$ perovskites, we need to form the weighted average values ${ }^{31}$ of the ionic radii of the atoms calculated by Shannon ${ }^{32}$ for different coordination numbers $(\mathrm{CN})$ and spin states [low spin (LS) and high spin (HS)]. The ionic radii of the cations are $1.36 \AA$ for $\mathrm{La} 3+_{(\mathrm{CN}: \mathrm{XII})} ; 1.42 \AA$ for $\mathrm{Sr} 2+_{(\mathrm{CN}: \mathrm{XII})} ; 0.645 \AA$ for $\mathrm{Fe} 3+_{(\mathrm{CN}: \mathrm{VI} \text { in } \mathrm{HS})} ; 0.585 \AA$ for $\mathrm{Fe} 4+_{(\mathrm{CN}: \mathrm{VI} \text { in } \mathrm{HS})} ; 0.56 \AA$ for $\mathrm{Ni3}+{ }_{(\mathrm{CN}: \mathrm{VI} \text { in } \mathrm{LS})} ; 0.60 \AA$ for $\mathrm{Ni3}+_{(\mathrm{CN}: \mathrm{VI} \text { in } \mathrm{HS})}$. The ionic radii of $\mathrm{O}^{2-}{ }_{(\mathrm{CN}: \mathrm{VI})}$ is $1.40 \AA \AA^{32}$

As long as the ions at the $\mathrm{A}$-site $\left(\mathrm{A}^{\prime}\right.$ and $\left.\mathrm{A}^{\prime \prime}\right)$ and $\mathrm{B}$-site $\left(\mathrm{B}^{\prime}\right.$ and $\left.\mathrm{B}^{\prime \prime}\right)$ are randomly distributed within the substituted perovskite $\mathrm{A}^{\prime}(1-\mathrm{x}) \mathrm{A}^{\prime \prime} \mathrm{xB}^{\prime}(1-\mathrm{y}) \mathrm{B}^{\prime \prime} \mathrm{yO}_{3-\delta}$, the tolerance factor needs to be rewritten to be able to calculate the weighted average of valences and ionic radius

$$
r_{\mathrm{A}}=(1-\mathrm{x}) \mathrm{La}^{3+}+\mathrm{xSr}^{2+} \text { and } \mathrm{r}_{\mathrm{B}}=(1-\mathrm{y}) \mathrm{Fe}^{\gamma}+\mathrm{yNi}^{3+} .
$$

In our calculation, $\mathrm{Ni}$ is considered as $\mathrm{Ni}^{3+}$ (Ref. 21) for both LS and HS state because we could not identify the actual spin state unambiguously. However, we are confident about the average oxidation state of $\mathrm{Fe}(\gamma)$ as a result of the LFMC for our Fe $L_{2,3}$ edge x-ray absorption spectra. The experimental spectra and their simulation with LFMC are compared for $\mathrm{LaFeO}_{3}$ and $25 \% \mathrm{Ni}$ doped $\mathrm{LaFe}_{0.75} \mathrm{Ni}_{0.25} \mathrm{O}_{3}$ in Fig. 4. The Slater integrals used in the calculation for $\mathrm{LaFeO}_{3}$ were scaled down to $70 \%$, as already exercised by Abbate $e t$ al. ${ }^{17}$ and for $\mathrm{LaFe}_{0.75} \mathrm{Ni}_{0.25} \mathrm{O}_{3}$ to $50 \%$ of their atomic values so as to mimic covalence effects. ${ }^{21}$ Thus it is clear that, once $\mathrm{Ni}$ is substituted to $\mathrm{LaFeO}_{3}$, it decreases the $d-d, p$ - $d$ interaction and $p$ - $d$ exchange interaction due to the fact that the Fe $3 d$ orbitals become broader and the overlap between Fe $3 d$ and $\mathrm{O} 2 p$ orbitals increases. Both, the pure $\mathrm{LaFeO}_{3}$ and the $\mathrm{Ni}$ substituted $\mathrm{LaFe}_{0.75} \mathrm{Ni}_{0.25} \mathrm{O}_{3}$ have $100 \% \mathrm{Fe}^{3+}$ in the HS $\mathrm{t}_{2 \mathrm{~g}}^{3} \mathrm{e}_{\mathrm{g}}^{2}\left({ }^{6} A_{1 g}\right)$ ground state. However, $25 \% \mathrm{Ni}$ substitution increases the crystal field from 1.80 to $1.85 \mathrm{eV}$.

The comparison for $\mathrm{x}=0.25,0.50$, and 0.75 was presented recently ${ }^{21}$ and is rewritten for the reader in Table II. Tolerance factors are calculated for both $\mathrm{Ni}^{3+}$ in $\mathrm{LS}$ and $\mathrm{HS}$, and the results are listed in Table II.

The calculated Goldschmidt tolerance factors for LSFN show a linear trend for both $\mathrm{Ni}^{3+}$ spin state species (see Fig.
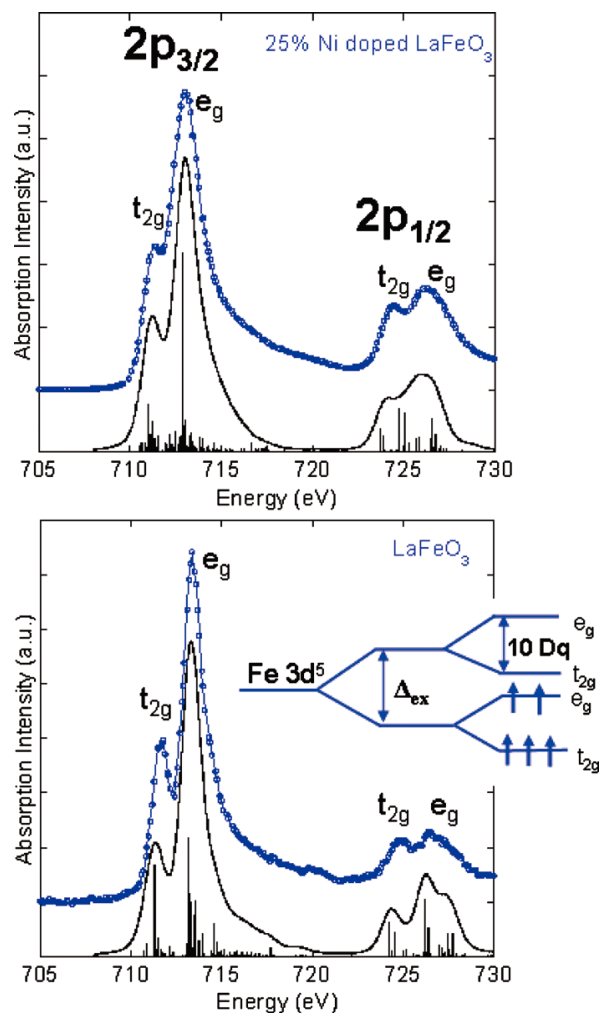

FIG. 4. (Color) Comparison between experimental (blue line with open symbols) and simulated (black line, bottom) $\mathrm{Fe}_{2,3}$ absorption spectra for $\mathrm{LaFeO}_{3}$ and $\mathrm{LaFe}_{0.75} \mathrm{Ni}_{0.25} \mathrm{O}_{3}$. Inset shows the electronic configuration of HS $\mathrm{Fe} 3 d^{5}$ in the ground state and modified after Abbate et al. (Ref. 17). Fe L edge split into $\mathrm{L}_{3}\left(2 p_{3 / 2}\right)$ and $\mathrm{L}_{2}\left(2 p_{1 / 2}\right)$ due to spin orbit coupling and additionally split into $t_{2 g}$ and $e_{g}$ levels due to crystal field effect. 
TABLE II. Average oxidation state of Fe, oxygen nonstoichiometry $(\delta)$, and the tolerance factor $(\mathrm{t})$ of LSFN with $\mathrm{Ni}^{3+}$ both in LS and HS states.[LS: Low spin state and HS: High spin state. $\mathrm{Both}_{\mathrm{Fe}^{3+}}$ and $\mathrm{Fe}^{4+}$ are in $\mathrm{HS}$ (Ref. 21).]

\begin{tabular}{ccccc}
\hline \hline Sr content $(\mathrm{x})$ & Oxidation state of $\mathrm{Fe}(\gamma)$ & $\delta$ & $\mathrm{t}\left(\mathrm{Ni}^{3+}\right.$ in $\left.\mathrm{LS}\right)$ & $\mathrm{t}\left(\mathrm{Ni}^{3+}\right.$ in HS $)$ \\
\hline 0.00 & $3.00\left(100 \% \mathrm{Fe}^{3+}+0 \% \mathrm{Fe}^{4+}\right)$ & 0.00 & 0.96436 & 0.95962 \\
0.25 & $3.25\left(75 \% \mathrm{Fe}^{3+}+25 \% \mathrm{Fe}^{4+}\right)$ & 0.035 & 0.97678 & 0.97196 \\
0.50 & $3.50\left(50 \% \mathrm{Fe}^{3+}+50 \% \mathrm{Fe}^{4+}\right)$ & 0.053 & 0.98933 & 0.98442 \\
0.75 & $3.95\left(5 \% \mathrm{Fe}^{3+}+95 \% \mathrm{Fe}^{4+}\right)$ & 0.069 & 1.00660 & 1.00150 \\
1.00 & $4.00\left(0 \% \mathrm{Fe}^{3+}+100 \% \mathrm{Fe}^{4+}\right)$ & $\cdots$ & 1.01490 & 1.00980 \\
\hline
\end{tabular}

5). The small differences in the ionic radii between $\mathrm{Ni}^{3+} \mathrm{LS}$ and HS reflect the differences in the tolerance factor. However, when $\mathrm{La}$ is replaced by $\mathrm{Sr}$, the tolerance factor starts to increase linear which is an evidence for an increase in the symmetry.

The sample with $\mathrm{x}=0$ has a smallest tolerance factor with $\mathrm{Ni}^{3+}$ high (low) spin $\mathrm{t}=0.960$ (0.964) for which $\mathrm{Ri}$ etveld analysis shows that it has orthorhombic symmetry. The samples with $\mathrm{x}=0.25, \mathrm{x}=0.50$, and $\mathrm{x}=0.75$ have tolerance factors with $\mathrm{Ni}^{3+}$ high (low) spin $\mathrm{t}=0.972(\mathrm{t}=0.977)$, $\mathrm{t}=0.984(\mathrm{t}=0.989)$, and $\mathrm{t}=1.002(\mathrm{t}=1.007)$ having rhombohedral symmetry. For $\mathrm{x}=1.0$, the tolerance factor is $\mathrm{t}$ $=1.015$ (1.010), and the sample has cubic symmetry. For SrTiO3 with ideal cubic symmetry, $t=1.00$ and for orthorhombic $\mathrm{GdFeO} 3, \mathrm{t}=0.81$ and it has been mentioned that cubic symmetry occurs for $0.89<\mathrm{t}<1.00 .^{33}$ For our samples, the cubic phase occurs when $\mathrm{t}>1.0$.

In perovskites, the A-site cation does not play a direct role on the conductivity but has an indirect influence: the Coulomb potential barrier formed by the A-site around the B-site cation affects the electron hole hopping process via the $\mathrm{Fe}^{3+}-\mathrm{O}-\mathrm{Fe}^{3+} / \mathrm{Fe}^{4+}$ superexchange unit. Therefore, the A-site Coulomb potential $\left(\mathrm{Z}_{\mathrm{A}} / \mathrm{r}_{\mathrm{A}}\right)$, where $\mathrm{Z}_{\mathrm{A}}$ and $\mathrm{r}_{\mathrm{A}}$ are the charge and ionic radius of A-site is calculated depending on $\mathrm{Sr}$ doping. For those samples which contain both $\mathrm{La}$ and $\mathrm{Sr}$, the weighted charge and radius are used for the calculation. The results are illustrated in Fig. 6, along with the $\mathrm{Fe} / \mathrm{Ni}-\mathrm{O}$ bond length.

As we can see in Fig. 6, the A-site Coulomb potential decreases linear with increasing $\mathrm{Sr}$ content. This is in line

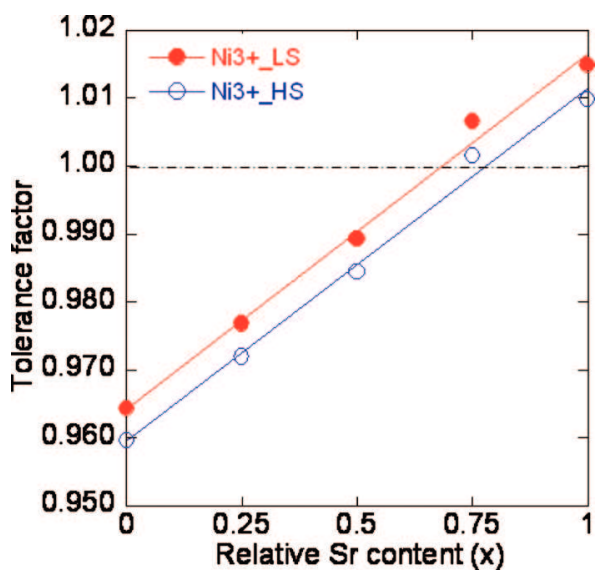

FIG. 5. (Color) Goldschmidt Tolerance factor of $\mathrm{La}_{1-\mathrm{x}} \mathrm{Sr}_{\mathrm{x}} \mathrm{Fe}_{0.75} \mathrm{Ni}_{0.25} \mathrm{O}_{3-\delta}$ depending on relative $\mathrm{Sr}$ content for $\mathrm{Ni}^{3+}$ both in LS and $\mathrm{HS}$. with our expectation because the valence state of $\mathrm{La}$ is $3+$ and doped with $\mathrm{Sr}$ of lower valence $\mathrm{Sr}^{2+}$ which has a larger ionic radius. The distance between iron or nickel, and the oxygen, $\mathrm{Fe} / \mathrm{Ni}-\mathrm{O}$ decreases linear up to $50 \% \mathrm{Sr}$ doping. For doping levels of $0.50<x \leq 1.0$ it approaches a constant value of around $1.925 \AA$. Therefore, the variation in the $\mathrm{Fe} / \mathrm{Ni}-\mathrm{O}$ distance deviates from the linear behavior of $\mathrm{Z}_{\mathrm{A}} / \mathrm{r}_{\mathrm{A}}$ for $\mathrm{x}$ $>0.50$, possibly because the system is not completely ionic but becomes more covalent.

\section{B. Electric conductivity}

The electrical conductivity of $\mathrm{La}_{1-\mathrm{x}} \mathrm{Sr}_{\mathrm{x}} \mathrm{Fe}_{0.75} \mathrm{Ni}_{0.25} \mathrm{O}_{3-\delta}$ was measured in the temperature range of $300 \mathrm{~K} \leq \mathrm{T}$ $\leq 1273 \mathrm{~K}^{21}$ Generally, the electric conductivity of perovskite oxide materials is related to small polaron hopping mechanism. ${ }^{4,10,11,34-36}$ This kind of perovskites shows similar behavior depending on temperature; the conductivity increases with increasing temperature like a semiconductor $(\mathrm{d} \rho / \mathrm{dT}<0)$ and then decreases similar to metallic behavior $(\mathrm{d} \rho / \mathrm{dT}>0){ }^{13,37}$ Furthermore, the transition temperature from semiconducting to metallic like behavior depends on the Sr doping. However, in this paper we limit ourselves to explain conductivity changes at $300 \mathrm{~K}$ depending on $\mathrm{Sr}$ content as shown in Fig. 7. The conductivity at $300 \mathrm{~K}$ increases with increasing $\mathrm{Sr}$ content up to $50 \%$ and then decreases. $\mathrm{Sr}$ doping in $\mathrm{LaFe}_{0.75} \mathrm{Ni}_{0.25} \mathrm{O}_{3}$ to $25 \%$ and $50 \%$ increases the conductivity by one and two orders of magnitude, respectively. However, for high $\mathrm{Sr}$ doping level (75\%), the conductivity decreases by one order of magnitude as compared to $50 \%$ doping. The sample with $\mathrm{x}=1.0$ was very brittle and could not be subjected to reliable conductivity measure-

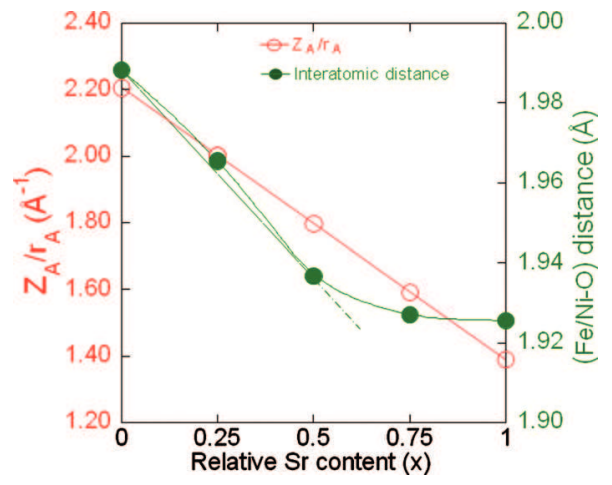

FIG. 6. (Color) A-site Coulomb potential and $\mathrm{Fe} / \mathrm{Ni}-\mathrm{O}$ distance of $\mathrm{La}_{1-\mathrm{x}} \mathrm{Sr}_{\mathrm{x}} \mathrm{Fe}_{0.75} \mathrm{Ni}_{0.25} \mathrm{O}_{3-\delta}$. 

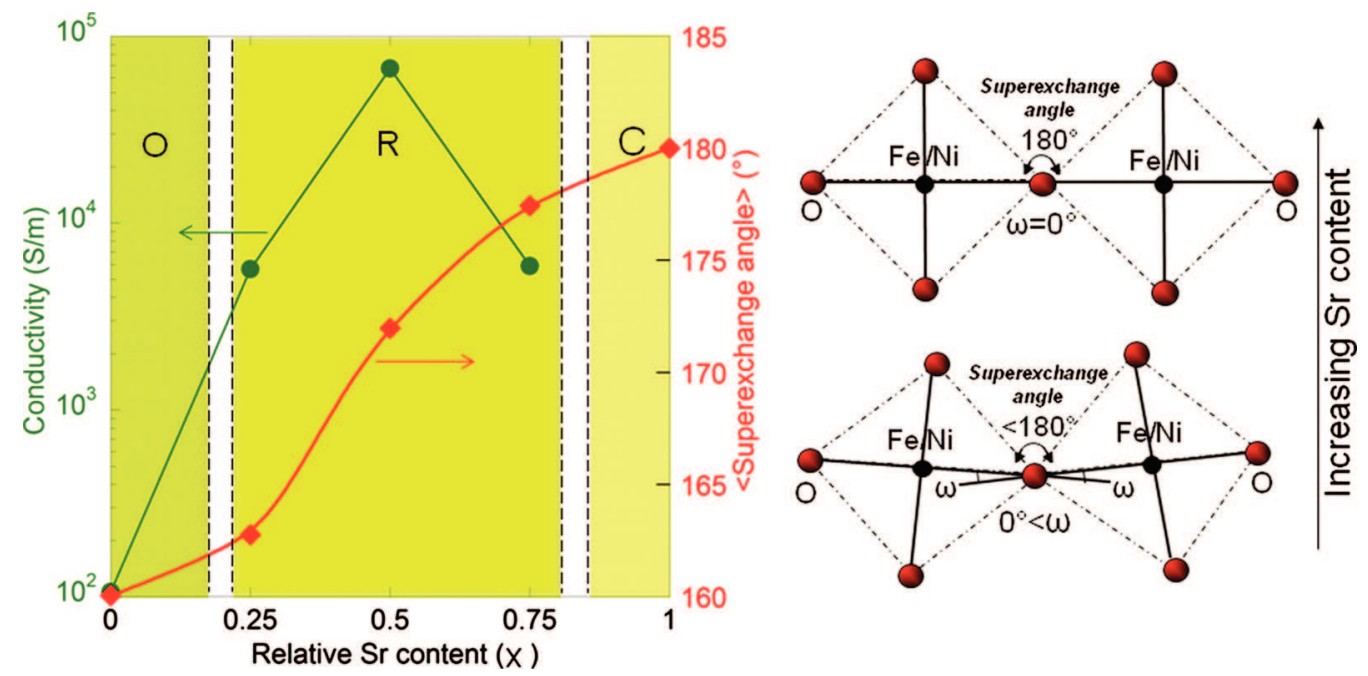

FIG. 7. (Color) Electrical conductivity at $300 \mathrm{~K}$ and superexchange angle depending on Sr content. A fragment of the rhombohedral/orthorhombic symmetry (Ref. 24) with a schematic representation of the average superexchange angle, $(\mathrm{Ni} / \mathrm{Fe}-\mathrm{O}-\mathrm{Ni} / \mathrm{Fe})$, and the average tilting angle, $\langle\omega\rangle$ which changes in to cubic symmetry with $180^{\circ}$ superexchange angle and $0^{\circ}$ tilting angle at high $\mathrm{Sr}$ doping. O, R, and $\mathrm{C}$ denote orthorhombic, rhombohedral, and cubic phases, respectively.

ments. However, test with multimeter tips showed a resistance in the megaohm range, suggesting that this material was an insulator.

\section{DISCUSSIONS}

The electrical conductivity is brought about by the conducting electron hole hopping process from $\mathrm{Fe}^{3+}$ to $\mathrm{Fe}^{4+}$ via the oxygen bridge $\left(\mathrm{Fe}^{3+}-\mathrm{O}^{2-}-\mathrm{Fe}^{4+}\right)$ in LSF, and we concluded that charge transfer from oxygen to nickel $(\mathrm{O}-\mathrm{Ni})$ contributes additionally to electrical conductivity in LSFN. ${ }^{21}$ Oxygen vacancies which interrupt the bridges between $\mathrm{O}$ and $\mathrm{Fe} / \mathrm{Ni}$ are undesirable not only from the point of hopping but also from the point of charge transfer contributions. The oxygen vacancy concentration is increased with increasing $\mathrm{Sr}$ content in the samples with the formula of $\mathrm{La}_{1-\mathrm{x}} \mathrm{Sr}_{\mathrm{x}} \mathrm{Fe}_{0.75} \mathrm{Ni}_{0.25} \mathrm{O}_{3}{ }^{21}$

In order to get more insight in the electrical conductivity we compare the sample with $\mathrm{x}=0$ (Ni doped LSF) with $\mathrm{LaFeO}_{3}$. The sample with $\mathrm{x}=0$ is a semiconductor while $\mathrm{LaFeO}_{3}$ is a charge transfer insulator at $300 \mathrm{~K}$. Replacing $\mathrm{Fe}$ by $\mathrm{Ni}$ causes a decrease in $\mathrm{B}-\mathrm{O}$ distance resulting in an increase in $\mathrm{O} 2 p$ bandwidth. Thus, the orbital overlap between $\mathrm{B} 3 d$ and $\mathrm{O} 2 p$ increases. ${ }^{38}$ This might be the reason why the sample with $\mathrm{x}=0$ has charge transfer from $\mathrm{O} 2 p$ to $\mathrm{Ni} 3 d$ which makes it conducting, in comparison to $\mathrm{LaFeO}_{3}$ despite their similar crystallographic symmetry (orthorhombic) and electronic configuration $3 d^{5}$ with total spin $\mathrm{S}=5 / 2$.

When we want to explain the A-site Sr doping effect on the conductivity, it is necessary to discuss numerous parameters such as electronic interaction, charge transfer, symmetry including superexchange and/or tilting angle, A-site potential and $\mathrm{B}-\mathrm{O}$ distance. Now that we have detailed quantitative information on the crystallographic structure and electronic structure of the LSFN samples, the electronic conductivity can be discussed and rationalized.

The sample with $\mathrm{x}=0$ having antiferromagnetic $\mathrm{Fe}^{3+}-\mathrm{O}^{2-}-\mathrm{Fe}^{3+}$ (Ref. 39) and spin related superexchange in- teraction shows the least charge transfer. The charge transfer mainly depends on the overlap between $\mathrm{O} 2 p$ and $\mathrm{Ni} 3 d$ orbitals and is maximum when the $\mathrm{Ni}-\mathrm{O}-\mathrm{Ni}$ superexchange angle is $180^{\circ}$ (cubic symmetry) or, in other words $\langle\omega\rangle=0$. Since this sample is in orthorhombic symmetry it has the largest deviation from the ideal cubic symmetry. The $\mathrm{Ni}-$ $\mathrm{O}-\mathrm{Ni}$ superexchange angle (tilting angle) is around $160^{\circ}$ $\left(\langle\omega\rangle \approx 9.98^{\circ}\right)$ with highest $\mathrm{B}-\mathrm{O}$ distance due to a strong A-site Coulomb potential and the least charge transfer.

The sample with $\mathrm{x}=0.25$ has a ferromagnetic$\mathrm{Fe}^{3+}-\mathrm{O}^{2-}-\mathrm{Fe}^{4+}$ (Ref. 39) hopping process with double exchange interaction where the conducting electrons jump from $\mathrm{Fe}^{3+}$ toward $\mathrm{Fe}^{4+}$ via the $\mathrm{O}$ bridge. As mentioned above, the A-site potential decreases when $\mathrm{La}^{3+}$ is replaced by $\mathrm{Sr}^{2+}$. This results in a decrease in $\mathrm{O}-\mathrm{Fe} / \mathrm{Ni}$ distance, an increase in the $\mathrm{O} 2 p$ bandwidth. Thus, the mobility of the electrons following double exchange process increases. In addition to that, the concentration of charge transferred electrons to $\mathrm{Ni} 3 d$ orbitals increases. Since the symmetry changes from orthorhombic to rhombohedral, the distortion is reduced $\left(\langle\omega\rangle=8.62^{\circ}\right)$ resulting in an increase in $\mathrm{Fe} / \mathrm{Ni}-\mathrm{O}-\mathrm{Fe} / \mathrm{Ni}$ superexchange angle of around $163^{\circ}$. This provides an additional increase in charge carrier mobility.

Similar rational applies to the sample with $\mathrm{x}=0.50$ : the A-site Coulomb potential decreases, the $\mathrm{Fe} / \mathrm{Ni}-\mathrm{O}$ distance gets shorter, keeps the symmetry rhombohedral with a lower distortion $\left(\langle\omega\rangle=8.03^{\circ}\right)$ and a larger $\mathrm{Fe} / \mathrm{Ni}-\mathrm{O}-\mathrm{Fe} / \mathrm{Ni}$ superexchange angle of around $172^{\circ}$, resulting in a increase in charge transfer. An important detail of the sample with $\mathrm{x}$ $=0.50$ is that the donor $\left(\mathrm{Fe}^{3+}\right)$ and acceptor $\left(\mathrm{Fe}^{4+}\right)$ concentrations are equal, which gives additional increase in charge carrier mobility. Consequently, this sample shows the highest electrical conductivity.

In the case of high $\mathrm{Sr}$ doping $(\mathrm{x}=0.75)$, the electrical conductivity decreases although the crystallographic symmetry comes closer to cubic with the $\mathrm{Fe} / \mathrm{Ni}-\mathrm{O}-\mathrm{Fe} / \mathrm{Ni}$ superexchange angle around $177^{\circ}$. Together with a weaker A-site 
potential consequently shorter $\mathrm{Fe} / \mathrm{Ni}-\mathrm{O}$ distance. That is why the sample has highest charge transfer. From this point, the sample is expected to show the highest electrical conductivity. On the other hand, this sample allows for the $\mathrm{Fe}^{3+}-\mathrm{O}^{2-}-\mathrm{Fe}^{4+}$ hopping process with double exchange interaction with $5 \%$ of donor and $95 \%$ acceptor resulting in a decrease in mobility of charge carriers. In addition to that, this sample has the highest oxygen vacancy concentration, which results in interruption of many oxygen bridges between $\mathrm{Fe} / \mathrm{Ni}-\mathrm{O}^{2-}-\mathrm{Fe} / \mathrm{Ni}$ superexchange unit, and results in a decrease in the double exchange. There are two mechanisms contributing electrical conductivity: charge transfer increases while the double exchange decreases. Since the electrical conductivity decreases in our experiment we can conclude that the decrease in double exchange is higher than the increase in the charge transfer and thus over compensates this effect. This also brings another conclusion concerning the oxygen vacancies. The vacancies are most probably created around the $\mathrm{Fe}$, and not around the $\mathrm{Ni}$ cation. If the oxygen vacancies were created around $\mathrm{Ni}$, the charge transfer form O $2 p$ to Ni $3 d$ orbitals would decrease upon increasing $\mathrm{Sr}$ content.

In $\mathrm{La}_{1-\mathrm{x}} \mathrm{Sr}_{\mathrm{x}} \mathrm{Fe}_{0.75} \mathrm{Ni}_{0.25} \mathrm{O}_{3-\delta}$, the Fe concentration is three times higher than the $\mathrm{Ni}$ concentration. Therefore, for all samples it is expected that the $\mathrm{Fe}^{3+}-\mathrm{O}^{2-}-\mathrm{Fe}^{4+}$ hopping process is dominant compared to charge transfer. At this point, it is worth to mention that we did not consider the hopping process across the $\mathrm{Ni}^{3+}-\mathrm{O}^{2-}-\mathrm{Ni}^{3+}$ superexchange unit: provided that the atoms are randomly distributed in $\mathrm{La}_{1-\mathrm{x}} \mathrm{Sr}_{\mathrm{x}} \mathrm{Fe}_{0.75} \mathrm{Ni}_{0.25} \mathrm{O}_{3-\delta}$ to lower the total energy of the system, the probability of having $\mathrm{Ni}$ atoms next to each other is negligibly small.

\section{CONCLUSIONS}

The crystallographic phase transformation from orthorhombic to rhombohedral symmetry and then to cubic is observed with increasing $\mathrm{Sr}$ content in $\mathrm{La}_{1-\mathrm{x}} \mathrm{Sr}_{\mathrm{x}} \mathrm{Fe}_{0.75} \mathrm{Ni}_{0.25} \mathrm{O}_{3}$ at room temperature. An increase in the calculated Goldschmidt tolerance factor shows that the symmetry of the system increases. The A-site potential is reduced by $\mathrm{Sr}$ substitution resulting in a decrease in the distance between $\mathrm{Fe} / \mathrm{Ni}-\mathrm{O}$ distance leading to an increase in overlap between $\mathrm{O} 2 p$ and $\mathrm{Fe} / \mathrm{Ni} 3 d$ orbitals.

The electrical conductivity mechanisms of $\mathrm{La}_{1-\mathrm{x}} \mathrm{Sr}_{\mathrm{x}} \mathrm{Fe}_{0.75} \mathrm{Ni}_{0.25} \mathrm{O}_{3}$ depending on the relative $\mathrm{Sr}$ content are discussed in terms of electron hopping with super/double exchange interaction and charge transfer. The effect of crystallographic changes on the conductivity is discussed in detail. In the low doping region $(0 \leq x \leq 0.50)$, both exchange interaction and charge transferred electron hole concentration increases with increasing $\mathrm{Sr}$ content, although in the high doping region $(x=0.75)$, the exchange mechanism decreases while the charge transfer increases. In order to test such speculations, density functional theory calculations may prove helpful. Such calculations are in progress, with particular focus on the projected density states and its modification upon doping.

\section{ACKNOWLEDGMENTS}

Financial support by the European Commission (MIRG Grant No. CT-2006-042095 and Real-SOFC Grant No. SES6-CT-2003-502612) and the Swiss National Science Foundation (SNF Grant No. 200021-116688) are acknowledged. The ALS is supported by the Director, Office of Science, Office of Basic Energy Sciences, of the U.S. Department of Energy under Contract No. DE-AC02-05CH11231. The authors would like to thank to Dr. Lynne McCusker from ETH-Zurich for helpful discussions on crystallographic structure results.

${ }^{1}$ C. Zener, Phys. Rev. 82, 403 (1951).

${ }^{2}$ J. B. Goodenough, Phys. Rev. 100, 564 (1955).

${ }^{3}$ U. Yu, J. H. Shim, B. H. Kim, B. I. Min, J. Magn. Magn. Mater. 310, 1660 (2007).

${ }^{4}$ T. Montini, M. Bevilacqua, E. Fonda, M. F. Casula, S. Lee, C. Tavagnacco, R. J. Gorte, and P. Fornasiero, Chem. Mater. 21, 1768 (2009).

${ }^{5}$ J. B. Torrance, P. Lacorre, A. I. Nazzal, E. J. Ansaldo, and C. Niedermayer, Phys. Rev. B 45, 8209 (1992).

${ }^{6}$ H. Falcon, A. E. Goeta, G. Punte, and R. E. Carbonio, J. Solid State Chem. 133, 379 (1997).

${ }^{7}$ M. Medarde, J. Mesot, S. Rosenkranz, P. Lacorre, W. Marshall, S. Klotz, J. S. Loveday, G. Hamel, S. Hull, and P. Radaelli, Physica B 234-236, 15 (1997).

${ }^{8}$ S. K. Park, T. Ishikawa, Y. Tokura, Y. Q. Li, and Y. Matsui, Phys. Rev. B 60, 10788 (1999).

${ }^{9}$ M. Bevilacqua, T. Montini, C. Tavagnacco, E. Fonda, P. Fornasiero, and M. Graziani, Chem. Mater. 19, 5926 (2007).

${ }^{10}$ K. Swierczek, J. Marzec, D. Palubiak, W. Zajac, and J. Molenda, Solid State Ionics 177, 1811 (2006).

${ }^{11}$ R. Chiba, F. Yoshimura, and Y. Sakurai, Solid State Ionics 124, 281 (1999).

${ }^{12}$ E. V. Tsipis, E. A. Kiselev, V. A. Kolotygin, J. C. Waerenborgh, V. A. Cherepanov, and V. V. Kharton, Solid State Ionics 179, 2170 (2008).

${ }^{13}$ R. Chiba, F. Yoshimura, and Y. Sakurai, Solid State Ionics 152-153, 575 (2002).

${ }^{14}$ A. Evans, A. Bieberle-Hütter, J. L. M. Rupp, and Ludwig J. Gauckler, J. Power Sources 194, 119 (2009).

${ }^{15}$ D. D. Sarma, O. Rader, T. Kachel, A. Chainani, M. Mathew, K. Holldack, W. Gudat, and W. Eberhardt, Phys. Rev. B 49, 14238 (1994).

${ }^{16}$ R. Kumar, J. Choudhary, W. Khan, P. Srivastava, W. Bao, M. Tsai, W. Chiou, K. Asokan, and W. F. Pong, J. Appl. Phys. 97, 093526 (2005).

${ }^{17}$ M. Abbate, F. M. F. de Groot, J. C. Fuggle, A. Fujimori, O. Strebel, F. Lopez, M. Domke, G. Kaindl, G. A. Sawatzky, M. Takano, Y. Takeda, H. Eisaki, and S. Uchida, Phys. Rev. B 46, 4511 (1992).

${ }^{18}$ A. Chainani, M. Mathew, and D. D. Sarma, Phys. Rev. B 48, 14818 (1993).

${ }^{19}$ H. Wadati, D. Kobayashi, H. Kumigashira, K. Okazaki, T. Mizokawa, A. Fujimori, K. Horiba, M. Oshima, N. Hamada, M. Lippmaa, M. Kawasaki, and H. Koinuma, Phys. Rev. B 71, 035108 (2005).

${ }^{20}$ F. M. F. de Groot, Chem. Rev. 101, 1779 (2001).

${ }^{21}$ S. Erat, A. Braun, A. Ovalle, C. Piamonteze, Z. Liu, T. Graule, and L. J. Gauckler, Appl. Phys. Lett. 95, 174108 (2009).

${ }^{22}$ A. C. Larson and R. B. von Dreele, Los Alamos National Laboratory Report No. LAUR-86-748, 1994 (unpublished).

${ }^{23}$ B. H. Toby, J. Appl. Crystallogr. 34, 210 (2001).

${ }^{24}$ E. Konysheva, E. Suard, and J. T. S. Irvine, Chem. Mater. 21, 5307 (2009).

${ }^{25}$ H. M. Rietveld, J. Appl. Crystallogr. 2, 65 (1969).

${ }^{26}$ A. M. Glazer, Acta Crystallogr., Sect. B: Struct. Crystallogr. Cryst. Chem. 28, 3384 (1972).

${ }^{27}$ V. M. Goldschmidt, Geochemistry (Oxford University Press, London, 1958).

${ }^{28}$ J. M. D. Coey, M. Viret, and S. von Molnar, Adv. Phys. 48, 167 (1999).

${ }^{29}$ J. B. Goodenough, Prog. Solid State Chem. 5, 145 (1971).

${ }^{30}$ M. Imada, A. Fujimori, and Y. Tokura, Rev. Mod. Phys. 70, 1039 (1998).

${ }^{31}$ N. Trofimenko and H. Ullmann, Solid State Ionics 118, 215 (1999).

${ }^{32}$ R. D. Shannon, Acta Crystallogr., Sect. A: Cryst. Phys., Diffr., Theor. Gen. Crystallogr. 32, 751 (1976).

${ }^{33} \mathrm{M}$. Johnsson and P. Lemmens, arXiv:cond-mat/0506606 (unpublished). 
${ }^{34}$ H. Taguchi, S. Matsu-ura, M. Nagao, and H. Kido, Physica B 270, 325 (1999).

${ }^{35}$ J. Dho and N. H. Hur, Solid State Commun. 138, 152 (2006).

${ }^{36}$ L. Wang, J. Yin, S. Huang, X. Hunag, J. Xu, Z. Liu, and K. Chen, Phys. Rev. B 60, 6976 (1999).

${ }^{37}$ A. Braun, J. Richter, A. S. Harvey, S. Erat, A. Infortuna, A. Frei, E.
Pomjakushina, B. S. Mun, P. Holtappels, U. Vogt, K. Conder, L. J. Gauckler, and T. Graule, Appl. Phys. Lett. 93, 262103 (2008).

${ }^{38}$ L. Mogni, F. Prado, H. Ascolani, M. Abbate, M. S. Moreno, A. Manthiram, and A. Canerio, J. Solid State Chem. 178, 1559 (2005).

${ }^{39}$ K. S. Ryu, S. J. Lee, and C. H. Yo, Bull. Korean Chem. Soc. 15, 256 (1994). 